\title{
Alcohol-free Hypoallergenic Barrier Film Solution
}

National Cancer Institute

\section{Source}

National Cancer Institute. Alcohol-free Hypoallergenic Barrier Film Solution. NCI

Thesaurus. Code C158820.

An alcohol-free, hypoallergenic, polymeric-cyanoacrylate-based solution that provides a barrier film, with potential skin protective and healing activities. Upon topical application of the barrier film solution to intact or damaged skin, the alcohol-free barrier film solution forms a breathable, transparent film over the skin and maintains and enhances skin integ rity, provides long-lasting protection against skin injury, infection, and irritation, and maintains moisture to the skin. 